\section{Recessive Resistance to Tomato yellow leaf curl virus from the Tomato Cultivar Tyking Is Located in the Same Region as $T y-5$ on Chromosome 4}

\author{
Samuel F. Hutton', Jay W. Scott, and David J. Schuster \\ Gulf Coast Research and Education Center, Institute of Food and \\ Agricultural Sciences, University of Florida, 14625 CR 672, Wimauma, \\ FL 33598-6101
}

Additional index words. begomovirus, disease resistance, Lycopersicon esculentum, Solanum lycopersicum, TYLCV, selective genotyping, transmission disequilibrium

\begin{abstract}
Tomato yellow leaf curl virus (TYLCV), a Begomovirus in the family Geminiviridae, is an important disease of cultivated tomato (Solanum lycopersicum $\mathrm{L}$.) in many parts of the world. Disease is managed primarily by chemical control of the vector, the sweetpotato whitefly, Bemisia tabaci (Genn.), and by growing resistant varieties. Resistance derived from the cultivar Tyking is being used in many breeding programs, but the location of resistance factors has not been reported. The breeding lines Fla. 8753 and Fla. 344 both have high levels of resistance to TYLCV derived from 'Tyking' and from $S$. chilense accession LA 1938, but none of their parent lines contain any of the known genes $T y-1$ to $T y-4$. An additional resistance locus, $T y-5$, was recently identified, and to determine if this locus controls TYLCV resistance in Fla. 8753 and Fla. 344, appropriate segregating populations were analyzed using the Ty-5 marker, SINAC1. Results show that SINACI cosegregates with a recessive allele derived from 'Tyking'. We suggest the gene symbol $t y-5$ be used to describe this gene. Mean disease severity of progeny homozygous for either the resistant or susceptible alleles did not equal parental levels of resistance and susceptibility, respectively, suggesting the involvement of an additional gene that is likely derived from LA1938.
\end{abstract}

Tomato yellow leaf curl virus is a major disease of cultivated tomatoes (Solanum lycopersicum L.) in many tropical and subtropical production regions of the world. TYLCV is a monopartite begomovirus in the family Geminiviridae and is transmitted by the sweetpotato whitefly, Bemisia tabacai (Genn.). Yield losses resulting from this virus have been severe (Polston and Anderson, 1997), and this disease is the major limiting factor in tomato production for many areas (Lapidot and Friedmann, 2002). Although chemical control of the vector can limit disease, epidemics can still occur, and whitefly resistance to the chemicals has been reported (Schuster et al., 2010). Much attention has focused on host resistance, and breeding efforts have relied on the transfer of resistant alleles from related wild species into the cultivated tomato, because no resistance has been found in the S. lycopersicum germplasm.

Resistance to TYLCV has been discovered in numerous wild tomato species, including S. pimpinellifolium, S. peruvianum, S. chilense, $S$. habrochaites, and $S$. cheesmaniae (Ji et al., 2007; Pico et al., 1996; Scott, 2007). To date, five resistance loci have been named. $T y-1$ was introgressed from the $S$. chilense accession LA1969 and mapped to chromosome 6 (Zamir

Received for publication 28 Oct. 2011. Accepted for publication 13 Jan. 2012.

${ }^{1}$ To whom reprint requests should be addressed; e-mailsfhutton@ufl.edu. clear from molecular marker analyses that this resistance is not based on $T y-1, T y-2, T y-3$, or $T y-4$ (Hutton and Scott, unpublished data). The source of resistance in 'Tyking' has been vague; it has been speculated that it is from a landrace in the Canary Islands or it was derived from S. peruvianum (Jaap Hoogstraten, personal communication). Because it is possible that $S$. peruvianum is the donor of resistance in 'Tyking', a number of these breeding lines were screened with the $T y$-5 CAPS marker, SINAC1 (Anbinder et al., 2009). On identification of an introgression on chromosome 4 in this material, we proceeded to determine if an association between this marker and resistance exists in this material. We report on a recessive allele from the cultivar Tyking that conditions resistance to TYLCV and maps to the $T y-5$ region.

\section{Materials and Methods}

Plant materials and experimental design. Two advanced breeding lines, each selected for resistance to both TYLCV and ToMoV over multiple seasons without the use of molecular markers, were used as donor parents to develop $F_{2}$ populations. Fla. 8753 is a fresh-market tomato with plum-shaped fruit that has a full vine and a high level of resistance. Breeding line Fla. 344 is a largefruited fresh-market tomato, also having a high level of resistance. Each of these lines has both 'Tyking' and the $S$. chilense accession LA 1938 in its pedigree, and each is homozygous for the introgression at the SINACl locus.

The susceptible breeding lines Fla. 8248, a large-fruited fresh-market tomato, and Fla. $7655 \mathrm{~B}$, a fresh-market plum tomato, were each crossed to Fla. 8753; and the $F_{1}$ from each of these crosses was self-pollinated to produce $\mathrm{F}_{2}$ seed. In Spring 2009, parent lines Fla. 8753 and Fla. $7655 \mathrm{~B}$, the susceptible control 'Horizon', and $294 \mathrm{~F}_{2}$ plants (84 plants from the Fla. 8248 population and 210 plants from the Fla. 7655 B population) were grown in the field in a randomized complete block design with three blocks. Inbred genotypes were planted in one six-plant plot per block, $F_{2}$ plants for the Fla. 8248 population were distributed evenly into one plot per block, and $\mathrm{F}_{2}$ plants of the Fla. 7655B population were distributed evenly into two plots per block. Plants were evaluated for TYLCV disease severity on 27 May as described subsequently. Individual $\mathrm{F}_{2}$ plants from each population were selected on the basis of highest or lowest levels of disease severity. $\mathrm{F}_{3}$ progeny lines of these selections were evaluated in Fall 2009, along with parents, in a randomized complete block design with three blocks and six-plant plots.

The susceptible breeding line Fla. 7547 was crossed to Fla. 344 , and the $\mathrm{F}_{1}$ from this cross was self-pollinated to produce $\mathrm{F}_{2}$ seed. In Fall 2009, the two parents and $121 \mathrm{~F}_{2}$ plants were grown in a randomized complete block design with three blocks and six-plant plots for inbred genotypes and 40-41 plant plots for the $F_{2}$. Plants were evaluated for TYLCV disease severity on 26 Oct. as described subsequently. 
Inoculation and disease evaluation. All plants were inoculated with whiteflies viruliferous for TYLCV according to the method of Griffiths and Scott (2001) with some modifications. Briefly, seedlings 3 weeks past the cotyledon stage (two to three leaves) were exposed to viruliferous whiteflies for 2 weeks in growth chambers. After inoculation, the whiteflies were killed by treating plants with an insecticidal soap and with Admire (imidacloprid), and the plants were transplanted to the field. Plants were rated for disease severity $\approx 40 \mathrm{~d}$ after exposure to whiteflies on a 0 to 4 disease severity index scale as described by Scott et al. (1996), where $0=$ no symptoms and $4=$ severe symptoms and stunting. Intermediate scores such as 1.5 , 2.5 , etc., were incorporated to allow for more precise disease severity ratings.

DNA extraction, molecular marker testing, and statistical analyses. DNA was extracted from young leaves of individual plants according to the protocol of Fulton et al. (1995). Primer sequences for the SINACl marker, polymerase chain reaction parameters, restriction digestion, and detection methods were described by Anbinder et al. (2009). Transmission disequilibrium at this locus was analyzed according to a modification of the test described by Zhu and Elston (2001). For this approach, disease severity scores of resistant and susceptible selections were regressed against their genotypic data on the basis of the probability of a resistant allele. Regression, analyses of variance, SE calculations, and Duncan's multiple range test were performed in SAS (Version 9.1; SAS Institute, Cary, NC).

\section{Results}

In Spring 2009, Fla. 8753 displayed a high level of resistance, and Fla. 7655B and 'Horizon' were highly susceptible to TYLCV (Table 1). Segregation of resistant and susceptible plants was clearly evident within each $F_{2}$ population, and a total of 33 resistant and 30 susceptible plants were selectively genotyped. The test for transmission disequilibrium at the SINACl locus was highly significant, indicating an effect of this locus on resistance (Table 2).

Most of the plants selectively genotyped in Spring 2009 were evaluated in Fall 2009 as $\mathrm{F}_{3}$ progeny lines for phenotypic confirmation. Of the 33 lines from resistant selections, 31 bred true for resistance, and 24 of these were homozygous for the 'Tyking' resistance allele; two resistant selections showed clear segregation among their $\mathrm{F}_{3}$ progeny and were also heterozygous at this locus. Of 27 lines from susceptible selections, 11 bred true for susceptibility, and 10 of these were homozygous for the susceptible allele at SINAC1 (data not shown). The other $16 \mathrm{~F}_{3}$ progeny lines corresponding to susceptible $F_{2}$ selections displayed clear segregation for resistance, and each plant of these lines was genotyped with the SINAC1 marker (Table 3). All except one of these lines segregated for the 'Tyking' allele at the $T y-5$ locus. Mean disease severity of plants homozygous for this allele was significantly lower than the mean disease severity of heterozygotes or homozygous susceptible genotypes. Additionally, mean disease severity of plants heterozygous at this locus was no different from mean disease severity of plants homozygous-susceptible, indicative of a recessive resistance gene. In light of these results, this locus is hereafter referred to as $t y-5$. Phenotypic segregation in some lines was fully explained by the $t y-5$ genotype (Fig. 1A); other lines, however, demonstrated segregation that

was not associated with SINACl (Fig. 1B-C), indicating that an additional gene may be affecting resistance. In support of this, the mean disease severity of $F_{3}$ plants homozygous for ty- 5 was significantly greater than that of Fla. 8753 , and mean disease severity of $F_{3}$ plants homozygous susceptible at this locus was significantly less than that of either susceptible parent.

Also in Fall 2009, $121 \mathrm{~F}_{2}$ progeny from the cross (Fla. $7547 \times$ Fla. 344 ) were evaluated

Table 1. Average Tomato yellow leaf curl virus disease severity index (DSI) for three inbred tomato lines in Spring 2009

\begin{tabular}{lll}
\hline Line & \multicolumn{1}{c}{ Description } & DSI \\
\hline Horizon & Susceptible control & $3.7^{\mathrm{A}} \pm 0.1(\mathrm{n}=18)$ \\
Fla. 7655B & Susceptible parent & $3.5^{\mathrm{A}} \pm 0.1(\mathrm{n}=17)$ \\
Fla. 8753 & Resistant parent & $1.1^{\mathrm{B}} \pm 0.1(\mathrm{n}=18)$ \\
\hline
\end{tabular}

Results are displayed as mean $\pm \mathrm{SE} ; \mathrm{n}=$ number of plants for each accession; DSI = disease severity index as described in the "Materials and Methods"; different superscript letters represent statistically significant differences at $P<0.05$ based on Duncan's multiple range test.

Table 2. Selective genotyping at the SINAC1 locus of resistant and susceptible $\mathrm{F}_{2}$ tomato plants grown in Spring 2009 and test for transmission disequilibrium.

\begin{tabular}{|c|c|c|c|c|c|c|c|}
\hline \multirow[b]{2}{*}{ Family } & \multirow[b]{2}{*}{ Phenotype } & \multirow[b]{2}{*}{ DSI } & \multicolumn{3}{|c|}{$\begin{array}{l}\text { Plant numbers for each } \\
\text { genotype at the } \\
\text { SINAC1 locus } \\
\end{array}$} & \multirow[b]{2}{*}{ Total } & \multirow{2}{*}{$\begin{array}{l}\text { Transmission } \\
\text { disequilibrium } \\
(P)\end{array}$} \\
\hline & & & $+/+$ & $+1-$ & $-1-$ & & \\
\hline$\overline{(\text { Fla. } 7655 B \times \text { Fla. } 8753) \mathrm{F}_{2}}$ & Resistant & $\leq 2.0$ & 14 & 7 & 0 & 21 & \\
\hline (Fla. $8248 \times$ Fla. 8753) $\mathrm{F}_{2}$ & & & 11 & 0 & 1 & 12 & \\
\hline Total & & & 25 & 7 & 1 & 33 & \\
\hline $\begin{array}{l}(\text { Fla. } 7655 \mathrm{~B} \times \text { Fla. } 8753) \mathrm{F}_{2} \\
(\text { Fla. } 8248 \times \text { Fla. } 8753) \mathrm{F}_{2} \\
\text { Total }\end{array}$ & Susceptible & $\geq 3.5$ & $\begin{array}{l}0 \\
0 \\
0\end{array}$ & $\begin{array}{r}11 \\
6 \\
17\end{array}$ & $\begin{array}{r}10 \\
3 \\
13\end{array}$ & $\begin{array}{r}21 \\
9 \\
30\end{array}$ & $<0.0001$ \\
\hline
\end{tabular}
index as described in the "Materials and Methods."

Table 3. Mean Tomato yellow leaf curl virus disease severity and genotype at the SINAC1 locus of $\mathrm{F}_{3}$ tomato progeny lines that segregated for resistance in Fall 2009.

\begin{tabular}{|c|c|c|c|c|}
\hline \multirow[b]{2}{*}{ Pedigree } & \multirow[b]{2}{*}{ Selection $^{y}$} & \multicolumn{3}{|c|}{ Mean DSI of plants in each genotypic category at $S I N A C 1^{z}$} \\
\hline & & $+/+$ & $+/-$ & $-1-$ \\
\hline Fla. $8248(8248)$ & S parent & & & $4.0^{\mathrm{A}} \pm 0.0(n=18)$ \\
\hline Fla. 7655B (7655B) & S parent & & & $4.0^{\mathrm{A}} \pm 0.0(n=18)$ \\
\hline Fla. $8753(8753)$ & $\mathrm{R}$ parent & $0.9^{D} \pm 0.1(n=18)$ & & \\
\hline$(8248 \times 8753)-B K-15$ & $\mathrm{~S}$ & $2.0 \pm 0.2(n=4)$ & $3.7 \pm 0.1(\mathrm{n}=7)$ & $3.5(\mathrm{n}=1)$ \\
\hline$(8248 \times 8753)-B K-35$ & $\mathrm{~S}$ & $2.5 \pm 0.3(\mathrm{n}=6)$ & $4.0 \pm 0.0(\mathrm{n}=11)$ & $4.0(\mathrm{n}=1)$ \\
\hline$(8248 \times 8753)-B K-37$ & $\mathrm{~S}$ & $2.1 \pm 0.2(\mathrm{n}=5)$ & $3.5 \pm 0.1(\mathrm{n}=8)$ & $3.5 \pm 0.2(\mathrm{n}=5)$ \\
\hline$(8248 \times 8753)-B K-56$ & $\mathrm{~S}$ & $2.0 \pm 0.2(\mathrm{n}=4)$ & $3.4 \pm 0.3(\mathrm{n}=7)$ & $3.5 \pm 0.1(\mathrm{n}=7)$ \\
\hline$(8248 \times 8753)-B K-63$ & $\mathrm{~S}$ & $2.9 \pm 0.2(\mathrm{n}=7)$ & $3.7 \pm 0.1(\mathrm{n}=7)$ & $3.9 \pm 0.1(n=4)$ \\
\hline$(8248 \times 8753)-B K-65$ & $\mathrm{~S}$ & $1.8 \pm 0.8(\mathrm{n}=3)$ & $3.1 \pm 0.3(\mathrm{n}=8)$ & $3.5 \pm 0.2(\mathrm{n}=5)$ \\
\hline$(7655 \mathrm{~B} \times 8753)-\mathrm{BK}-95$ & $\mathrm{R}$ & $1.5 \pm 0.2(\mathrm{n}=5)$ & $3.0 \pm 0.2(\mathrm{n}=8)$ & $2.9 \pm 0.3(\mathrm{n}=3)$ \\
\hline$(7655 \mathrm{~B} \times 8753)-\mathrm{BK}-109$ & $\mathrm{~S}$ & $1.5 \pm 0.0(\mathrm{n}=2)$ & $3.6 \pm 0.2(\mathrm{n}=5)$ & $3.5 \pm 0.1(\mathrm{n}=10)$ \\
\hline$(7655 \mathrm{~B} \times 8753)-\mathrm{BK}-118$ & $\mathrm{~S}$ & $2.5(\mathrm{n}=1)$ & $3.6 \pm 0.2(\mathrm{n}=6)$ & $3.5 \pm 0.3(\mathrm{n}=3)$ \\
\hline$(7655 \mathrm{~B} \times 8753)-\mathrm{BK}-137$ & $\mathrm{~S}$ & $2.3 \pm 0.3(\mathrm{n}=2)$ & $3.4 \pm 0.2(\mathrm{n}=8)$ & $3.7 \pm 0.1(\mathrm{n}=5)$ \\
\hline$(7655 \mathrm{~B} \times 8753)-\mathrm{BK}-153$ & $\mathrm{~S}$ & $1.5 \pm 0.2(\mathrm{n}=6)$ & $3.5 \pm 0.1(n=6)$ & $3.5 \pm 0.0(\mathrm{n}=2)$ \\
\hline$(7655 \mathrm{~B} \times 8753)-\mathrm{BK}-157$ & $\mathrm{~S}$ & $2.3 \pm 0.2(\mathrm{n}=2)$ & $3.9 \pm 0.1(\mathrm{n}=7)$ & $3.8 \pm 0.1(n=4)$ \\
\hline$(7655 \mathrm{~B} \times 8753)-\mathrm{BK}-161$ & $\mathrm{~S}$ & NA & $\mathrm{NA}$ & $3.3 \pm 0.1(\mathrm{n}=18)$ \\
\hline$(7655 \mathrm{~B} \times 8753)-\mathrm{BK}-162$ & $\mathrm{~S}$ & $2.0 \pm 0.3(\mathrm{n}=7)$ & $3.3 \pm 0.1(\mathrm{n}=7)$ & $3.1 \pm 0.2(n=4)$ \\
\hline$(7655 \mathrm{~B} \times 8753)-\mathrm{BK}-166$ & $\mathrm{~S}$ & $2.8 \pm 0.8(n=2)$ & $3.2 \pm 0.2(\mathrm{n}=9)$ & $3.4 \pm 0.2(n=4)$ \\
\hline$(7655 \mathrm{~B} \times 8753)-\mathrm{BK}-175$ & $\mathrm{~S}$ & $1.5 \pm 0.0(n=2)$ & $3.6 \pm 0.1(\mathrm{n}=8)$ & $3.5 \pm 0.0(n=4)$ \\
\hline $\mathrm{F}_{3}$ progeny mean & & $2.1^{\mathrm{C}}$ & $3.5^{\mathrm{B}}$ & $3.5^{\mathrm{B}}$ \\
\hline
\end{tabular}

${ }^{\mathrm{z}}$ Results are displayed as mean $\pm \mathrm{SE} ;+/+=$ homozygous-resistant; $+/-=$ heterozygous; $-/-=$ homozygoussusceptible; $n$ number of plants in each accession; DSI $=$ disease severity index as described in the "Materials and Methods"; different superscript letters represent statistically significant differences at $P<$ 0.05 based on Duncan's multiple range test.

${ }^{\mathrm{y}} \mathrm{S}=$ susceptible; $\mathrm{R}=$ resistant.

$\mathrm{NA}=$ not applicable. 
for TYLCV disease severity and genotyped using the SINAC1 marker. Results confirmed the effect of a recessive gene on chromosome 4 (Table 4). Again, mean disease severity of progeny homozygous for ty-5 was significantly higher than that of the resistant parent, whereas mean disease severity of progeny homozygous for the susceptible allele was significantly lower than that of the susceptible parent. In support of these results, a significant amount of the phenotypic variation was not explained by the SINAC1 marker $\left(R^{2}=0.66\right)$. These data again suggest that there may be an additional resistance gene involved, because homozygosity of the ty-5 allele did not on average equal parental levels of resistance, and absence of this allele did not on average equal parental levels of susceptibility.

\section{Discussion}

The begomovirus resistance gene, $T y-5$, was recently discovered in the breeding line TY172 derived from $S$. peruvianum; this gene was mapped to chromosome 4 near the marker SlNACl (Anbinder et al., 2009). Results presented here show that this marker cosegregates with a resistance allele derived from the cultivar Tyking. In the early 1990s, the University of Florida tomato breeding program initiated a begomovirus resistance breeding project, which primarily relied on several $S$. chilense accessions as donors of resistance. 'Tyking' was also evaluated in the program, and $\mathrm{F}_{2}$ seed was developed by selfpollinating the hybrid. In 1995, $20 \mathrm{~F}_{2}$ plants were inoculated with $\mathrm{ToMoV}$ and evaluated for resistance; all 20 plants showed partial resistance with no segregation for resistance observed. This resistance was incorporated into the program by combining it with resistance derived from $S$. chilense accession LA 1938. It is clear that $t y-5$ is descended from 'Tyking' rather than LA 1938, because the former is homozygous for the resistant allele, whereas the parents with LA 1938derived resistance are homozygous for the susceptible allele (data not shown).

The present study clearly shows that the 'Tyking'-derived allele is recessive, which explains why no segregation was observed among the $\mathrm{F}_{2}$ plants derived from this hybrid in 1995. One of the $F_{2}$ populations used by Anbinder et al. (2009) to characterize $T y-5$ resistance (i.e., TY172 $\times$ M-82) also indicated recessive gene action. We therefore suggest the TY172-derived locus be renamed $t y-5$ to reflect the recessive gene action, although allelism of the genes in 'Tyking' and TY172 has yet to be proven. It would be useful to evaluate the resistance genes from both sources in similar backgrounds to determine if they provide comparable levels of resistance against different begomoviruses.

Bian et al. (2007) determined that resistance from Fla. 653 was conditioned by a recessive allele, tgr-1; Fla. 653 and other Florida breeding lines presented in that study have resistance derived from 'Tyking' and are homozygous for $t y-5$ (data not shown). Giordano et al. (2005) also identified a recessive allele
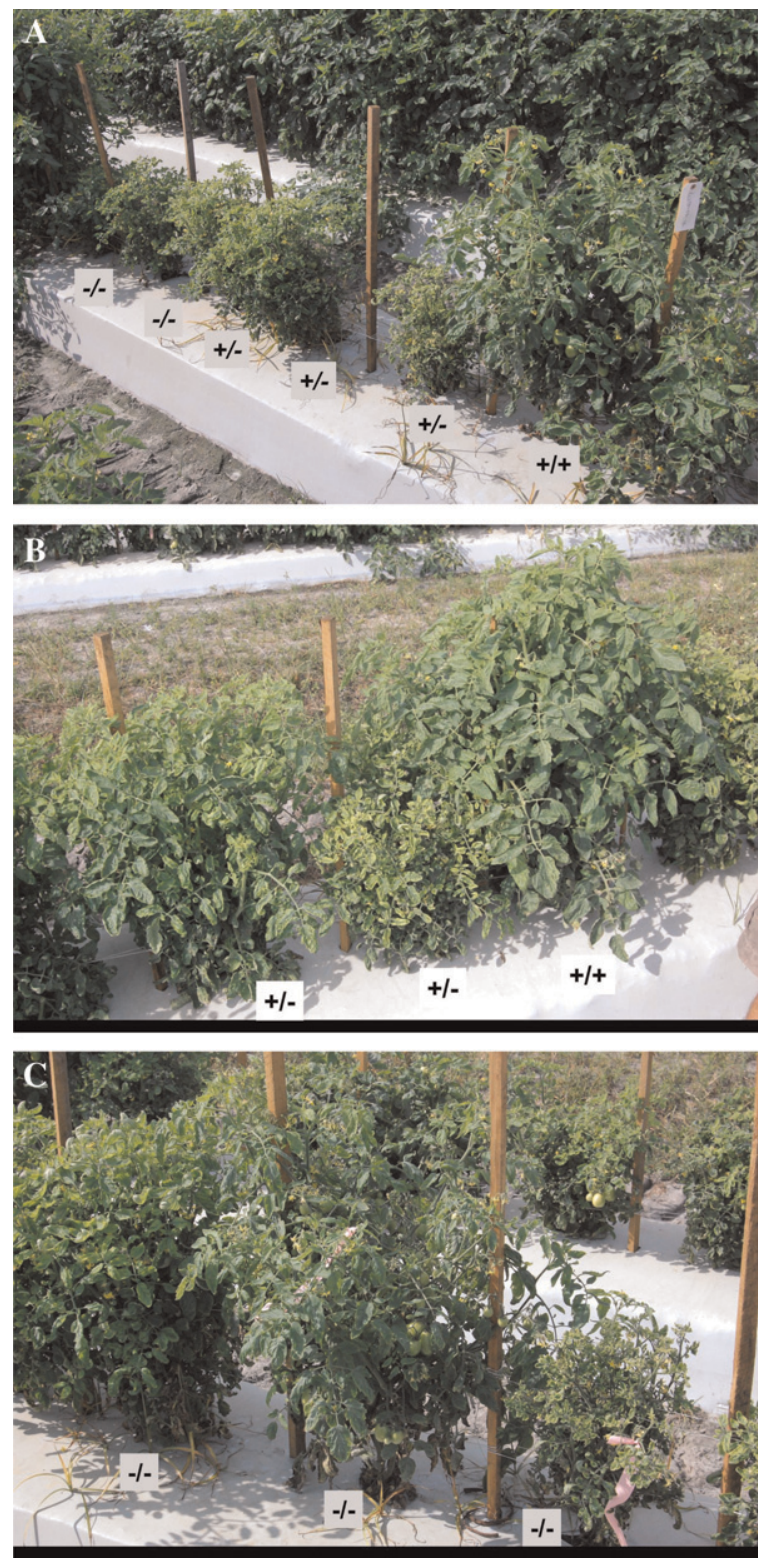

Fig. 1. Tomato yellow leaf curl virus (TYLCV) symptom expression and genotype at the SINAC1 locus of $\mathrm{F}_{3}$ tomato progeny segregating for TYLCV resistance in Fall 2009. $+/+=$ homozygous-resistant; $+/-=$ heterozygous; $-/-=$ homozygous-susceptible. (A) $($ Fla. $7655 \mathrm{~B} \times$ Fla. 8753$)$-BK-157 progeny segregating only for $t y-5$; (B) (Fla. $7655 \mathrm{~B} \times$ Fla. 8753$)$-BK-118 progeny segregating for both $t y-5$ and an additional resistance allele; $(\mathbf{C})($ Fla. $7655 \mathrm{~B} \times$ Fla. 8753$)$-BK-161 progeny segregating only for an additional resistance allele.

Table 4. Mean Tomato yellow leaf curl virus disease severity and genotype at the SINAC1 locus of $\mathrm{F}_{2}$ tomato progeny and their parents in Fall 2009.

\begin{tabular}{lcc}
\hline Line & Genotype at the SlNACl locus $^{\mathrm{z}}$ & Mean DSI $^{\mathrm{y}}$ \\
\hline Fla. 7547 (susceptible parent) & $-/-$ & $4.0^{\mathrm{A}} \pm 0.0(\mathrm{n}=18)$ \\
Fla. 344 (resistant parent) & $+/+$ & $1.1^{\mathrm{D}} \pm 0.1(\mathrm{n}=18)$ \\
(Fla. 7547 $\times$ Fla. 344) F $\mathrm{F}_{2}$ & $+/+$ & $1.8^{\mathrm{C}} \pm 0.1\left(\mathrm{n}=34^{\mathrm{x}}\right)$ \\
& $+/-$ & $3.4^{\mathrm{B}} \pm 0.1(\mathrm{n}=59)$ \\
& $-/-$ & $3.3^{\mathrm{B}} \pm 0.1(\mathrm{n}=28)$ \\
\hline
\end{tabular}

$\mathrm{z}_{+} /+=$homozygous-resistant $;+/-=$heterozygous; $-/-=$homozygous-susceptible.

y DSI = disease severity index as described in the "Materials and Methods"; results are displayed as mean \pm $\mathrm{SE} ; n$ number of plants in each accession; different superscript letters represent statistically significant differences at $P<0.05$ based on Duncan's multiple range test.

${ }^{\times} \mathrm{F}_{2}$ segregation fits a $1: 2: 1(+/+:+/-:-/-)$ ratio $\left[\chi^{2}=0.669, P\left(\chi^{2}\right)=0.72,2 \mathrm{df}\right]$, and a $3: 1(+/+:-/-)$ ratio $\left[\chi^{2}\right.$ $\left.=0.620, P\left(\chi^{2}\right)=0.43,1 \mathrm{df}\right]$.

(tcm-1) from 'Tyking' that was effective against bipartite begomoviruses. We hypothesize that tgr -1 and $t c m-1$ both describe the ty-5 allele from 'Tyking', and we speculate that this allele was introgressed from $S$. peruvianum. Researchers in other areas who are using resistance derived from 'Tyking' should test ty-5 markers to confirm that this locus 
cosegregates with resistance in their materials; if so, ty-5 should be effective against multiple monopartite and bipartite begomoviruses around the world. It is presently unclear how tightly SINACl is linked to $t y-5$, and more work is needed to determine this. This marker did not explain all of the variation in our populations, which might suggest that there was recombination between the marker and the gene. This explanation would account for the higher levels of resistance observed in the resistant parent than in $\mathrm{F}_{2}$ progeny homozygous for ty 5 , because recombinant plants that were homozygous resistant for the marker yet heterozygous for the allele would have scored as susceptible phenotypically. However, this explanation would not account for the greater susceptibility observed in the susceptible parents relative to $\mathrm{F}_{2}$ plants homozygous susceptible at SINAC1, because crossovers yielding plants heterozygous for the gene would have still scored as susceptible phenotypes. Overall the data more likely indicate that another resistance allele is segregating in our populations. The effect of a second resistance allele explains how plant $(7655 \mathrm{~B} \times 8753)-\mathrm{BK}-95$ was selected as resistant, although it was heterozygous for $t y-5$ (Table 3); and a second allele also explains the segregation observed in progeny from $(7655 \mathrm{~B}$ $\times$ 8753)-BK-161, which were fixed for ty-5 (Table 3; Fig. 1C). Considering the pedigree of the material, along with the fact that only partial resistance was recovered in the 'Tyking' $-F_{2}$, it is likely that this allele is derived from LA 1938. A population developed from another 'Tyking'/LA 1938-derived breeding line, Fla. $8638 \mathrm{~B}$, has also shown segregation for resistance, which is not the result of ty-5 or any other identified locus (Hutton, unpublished data). Likewise, Fla. 8383 is an advanced breeding line with partial resistance derived from $S$. chilense accession LA 2779 but which contains none of the mapped resistance loci $T y-1$ through $t y$-5. Complementation tests between Fla. $8638 \mathrm{~B}$ and Fla. 8383 indicate that the additional resistance locus in Fla. $8638 \mathrm{~B}$ is likely allelic to the resistance locus in Fla. 8383, because evaluation of nearly $94 \mathrm{~F}_{2}$ progeny in Fall 2009 and Spring 2010 indicated a partial level of resistance in all plants with no observable segregation (data not shown). Efforts are underway to map this locus and to characterize the resistance it provides.

Our results have clear implications for breeders using 'Tyking' as a source of resistance. The fact that $t y-5$ functions recessively means it will need to be incorporated into both parents of a hybrid, yet the ability to use linked markers will allow for efficient incorporation of this allele into advanced material by marker-assisted selection. However, as our data indicate, higher levels of resistance are obtained when $t y-5$ is combined with the additional resistance gene, as was the case in the parent lines Fla. 8753 and Fla. 344. It can also be combined with other resistance genes. The single dominant genes $T y-1$ and $T y$ - 2 have failed in some production regions (Scott, 2007; Scott, personal communication). Pyramiding of resistance genes may ameliorate these problems. Mejia et al. (2010) showed that a line homozygous for $T y-2$ alone was susceptible to bipartite begomoviruses in Guatemala. However, resistance from a line heterozygous for $T y-2$ combined with heterozygous $T y-3 a$ was enhanced over a line heterozygous for $T y-3 a$ alone. Vidavski (2007) also showed that combining different resistance genes from two parents sometimes resulted in TYLCV resistance greater than that of either parent separately. As more resistance genes are mapped, molecular markers can be used to help develop lines with various combinations of alleles for testing in production regions of interest. It would be logical for breeders to focus on the simplest gene combinations that provide adequate resistance for given situations so that acceptable horticultural attributes can be realized along with the resistance.

\section{Literature Cited}

Anbinder, I., M. Reuveni, R. Azari, I. Paran, S. Nahon, H. Shlomo, L. Chen, M. Lapidot, and I. Levin. 2009. Molecular dissection of Tomato leaf curl virus resistance in tomato line TY172 derived from Solanum peruvianum. Theor. Appl. Genet. 119:519-530.

Bian, X.Y., M.R. Thomas, M.S. Rasheed, M Saeed, P. Hanson, P.J. De Barro, and M.A. Rezaian. 2007. A recessive allele (tgr- 1 ) conditioning tomato resistance to geminivirus infection is associated with impaired viral movement. Phytopathology 97:930-937.

Fulton, T.M., J. Chunwongse, and S.D. Tanksley. 1995. Microprep protocol for extraction of DNA from tomato and other herbaceous plants. Plant Mol. Biol. Rpt. 13:207-209.

Giordano, L.B., V.L. Silva-Lobo, F.M. Santana, M.E.N. Fonseca, and L.S. Boiteux. 2005. Inheritance of resistance to the bipartite Tomato chlorotic mottle begomovirus derived from Lycopersicon esculentum cv. 'Tyking'. Euphytica 143:27-33

Griffiths, P.D. and J.W. Scott. 2001. Inheritance and linkage of tomato mottle virus resistance genes derived from Lycopersicon chilense accession LA 1932. J. Amer. Soc. Hort. Sci. 126 : 462-467.

Hanson, P., S.K. Green, and G. Kuo. 2006. Ty-2, a gene on chromosome 11 conditioning geminivirus resistance in tomato. Rpt. Tomato Genet. Coop. 56:17-18.

Hanson, P.M., D. Bernacchi, S. Green, S.D Tanksley, M. Venkataramappa, A.S. Padmaja, H. Chen, G. Kuo, D. Fang, J. Chen, V. Muniyappa, H.M. Chen, and J.T. Chen. 2000. Mapping a wild tomato introgression associated with tomato yellow leaf curl virus resistance in a cultivated tomato line. J. Amer. Soc. Hort. Sci. 125:15-20.

Ji, Y., J.W. Scott, P. Hanson, E. Graham, and D.P. Maxwell. 2007. Sources of resistance, inheritance, and location of genetic loci conferring resistance to members of the tomato-infecting begomoviruses, p. 343-362. In: Czosnek, H. (ed.). Tomato yellow leaf curl virus disease: Management, molecular biology, breeding for resistance. Springer, Dordrecht, The Netherlands.

Ji, Y., J.W. Scott, D.J. Schuster, and D.P. Maxwell. 2009. Molecular mapping of Ty-4, a new Tomato Yellow Leaf Curl Virus resistance locus on chromosome 3 of tomato. J. Amer. Soc. Hort. Sci. 134:281-288.

Kalloo, G. and M.K. Baanerjee. 1990. Transfer of tomato leaf curl virus resistance from Lycopersicon hirsutum f. glabratum to L. esculentum. Plant Breed. 105:156-159.

Lapidot, M. and M. Friedmann. 2002. Breeding for resistance to whitefly-transmitted geminiviruses. Ann. Appl. Biol. 140:109-127.

Mejia, L., R.E. Teni, B.E. Garcia, A.C. Fulladolsa, and L. Mendez. 2010. Preliminary observations on the effectiveness of five introgressisons for resistance to begomoviruses in tomatoes. Rpt. Tomato Genet. Coop. 60:41-53.

Pico, B., J. Diez Maria, and F. Nuez. 1996. Viral diseases causing the greatest economic losses to the tomato crop. II: The tomato yellow leaf curl virus-A review. Sci. Hort. 67:151-196.

Polston, J.E. and P.K. Anderson. 1997. The emergence of whitefly-transmitted geminiviruses in tomato in the western hemisphere. Plant Dis. 81:1358-1369.

Santana, F.M., S.G. Ribeiro, A.W. Moita, D.J. Moreira, Jr., and L.B. Biordano. 2001. Sources of resistance in Lycopersicon spp. to a bipartite whitefly-transmitted geminivirus from Brazil. Euphytica 122:45-51

Schuster, D.J., R.S. Mann, M. Toapanta, R. Cordero, S. Thompson, S. Cyman, A. Shurtleff, and R.F. Morris. 2010. Monitoring neonicotinoid resistance in biotype B of Bemisia tabaci in Florida. Pest Mgt. Sci. 66:186-195.

Scott, J.W. 2001. Geminivirus resistance derived from Lycopersicon chilense accessions LA 1932, LA 1938, and LA 2779. 11 Feb. 2012. <http:// tgc.ifas.ufl.edu/2001/TBRT01Abstracts.pdf>.

Scott, J.W. 2007. Breeding for resistance to viral pathogens, p. 457-485. In: Razdan, M.K., and A.K. Mattoo (eds.). Genetic improvement of solanaceous crops, vol. 2: Tomato. Science Publ., Enfield, MA.

Scott, J.W., M.R. Stevens, J.H.M. Barten, C.R Thome, J.E. Polston, D.J. Schuster, and C.A. Serra. 1996. Introgression of resistance to whitefly-transmitted geminiviruses from Lycopersicon chilense to tomato, p. 357-367. In: Gerling, D. and R.T. Mayer (eds.). Bemisia 1995: Taxonomy, biology, damage control, and management. Intercept Ltd., Andover, Hants, UK

Vidavski, F. 2007. Exploitation of resistance genes found in wild tomato species to produce resistant cultivars; Pile up of resistant genes, $\mathrm{p}$. 363-372. In: Czosnek, H. (ed.). Tomato yellow leaf curl virus disease: Management, molecular biology, breeding for resistance. Springer, Dordrecht, The Netherlands.

Zamir, D., I. Ekstein-Michelson, Y. Zakay, N. Navot, M. Zeidan, M. Sarfatti, Y. Eshed, E. Harel, T. Pleban, H. van-Oss, N. Kedar, H.D. Rabinowitch, and H. Czosnek. 1994. Mapping and introgression of a tomato yellow leaf curl virus tolerance gene, TY-1. Theor. Appl. Genet. $88: 141-146$

Zhu, X. and R.C. Elston. 2001. Transmission disequilibrium test for quantitative traits. Genet. Epidemiol. 20:57-74. 